\title{
Görme Kaybı ile Başvuran Gebede Posterior Reversibl Ensefalopati Sendromu (PRES): Olgu Sunumu
}

Posterior Reversible Encephalopathy Syndrome (PRES) in a Pregnant with Blindness: A Case Report

\author{
Ayşe Yasemin Karageyim Karşıdağ ${ }^{1}$, Esra Esim Büyükbayrak ${ }^{1}$, Seda Subaş ${ }^{1}$ \\ Erdinç Şişman ${ }^{1}$, Seviye Bora Şişman ${ }^{2}$
}

1. Dr. Lütfi Kırdar Kartal Eğitim ve Araştırma Hastanesi Kadın Hastalıkları ve Doğum Kliniği, İstanbul, Türkiye 2. Siyami Ersek Eğitim ve Araştırma Hastanesi Radyoloji Kliniği, Istanbul, Turkiye

\section{$\ddot{O Z Z E T}$}

Posterior Reversibl Ensefalopati Sendromu (PRES) görme bozukluklart, mental durum bozukluğu ve nöbetler ile seyreden bir sendromdur. Bilgisayarl tomografi (BT) ve magnetik rezonans (MR) görüntülemede oksipital, temporal ve pariyetal lobda ödem mevcuttur. Sikllkla ani yükselen ve kompanse edilemeyen arter basıncına bağl olarak; preeklampsi, böbrek yetmezliği, enfeksiyonlar ve immunosüpressif ilaçlar zemininde gelişir. PRES 'in erken tanı ve tedavisi önemlidir. PRES medikal acillerden biridir ve özellikle erken tanı ve hizlı tedavi ile tamamen geri dönüşümlü bir sendromdur. Burada görme kaybı ile başvuran, preeklampsi zemininde gelişen ve MR ile tanisı konulan PRES sendromu olgusunu sunduk.

Anahtar Kelimeler: posterior reversibl ensefalopati sendromu, gebelik, preeklampsi

\section{ABSTRACT}

Posterior Reversible Encephalopathy Syndrome (PRES) is characterized by clinical symptoms such as visual disturbance, altered mental status, and seizures. It also presented with abnormal findings on computed tomography (CT) and magnetic resonance imaging (MRI) indicating cerebral edema in the occipital, temporal, and parietal lobes. It is often related with an acute increase in arterial blood pressure, and is associated with preeclampsia, renal failure, infections, and immunosuppressive agents. Early diagnosis and treatment of PRES is very important. PRES is a medical emergency and it is a fully reversible condition especially when diagnosed and treated immediately. Herein we report a case presented with blindness and diagnosed with MRI as PRES

Keywords: posterior reversible encephalopathy syndrome, pregnancy, preeclampsia

\footnotetext{
İletişim Bilgileri:

Yazışmadan Sorumlu Yazar: Ayşe Y. K. KARŞIDAĞ

Yazışma Adresi: Dr. Lütfi Kirdar Kartal Eğt. ve Araştırma Hastanesi Kadın Hastalıkları ve Doğum Kliniği, Istanbul

E-mail: ykarageyim@yahoo.com

Makalenin Geliş Tarihi: 08.08.2014

Makalenin Kabul Tarihi: 25.12.2014
}

\section{GİRIȘ}

PRES santral sinir sistemini etkileyen hem erișkin hem de çocuklarda gelișen nadir ve ciddi bir sendromdur [1, 2]. Baş ağrısı, görme bozukluğu, nöbet ve mental durum bozukluğu gibi bulguları olan, etiyolojik faktörün ortadan kaldırılması ile birkaç haftada klinik ve radyolojik olarak düzelebilen bir tablodur. Etiyolojide hipertansif ensefalopati, preeklampsi, akut ve kronik böbrek hastalıkları, sitotoksik ve immünosüpresif ilaçlar, kan transfüzyonu ve elektrolit dengesizliği yer alır. Patofizyolojik mekanizmada hiperperfüzyona bağlı serebral arteriollerde kaçak veya vasküler endotelin hasarı sorumlu tutulmuştur [3].

$\mathrm{Bu}$ olgu sunumunda, gebeliğinin 38 . haftasında görme kaybı ve bilinç bulanıklığı ile başvuran, postpartum dönemde konvülsiyonların eşlik ettiği ve preeklampsiye sekonder gelişen PRES sendromunu literatür eşliğinde tartışmayı amaçladik.

\section{OLGU}

On dokuz yaşında, son adet tarihine göre 38 hafta 4 günlük gebeliği olan hasta görme kaybı ve zaman zaman bilinç bulanıklığ ile acil kadın hastalıkları ve doğum kliniğimize getirildi. İki gündür bulantı - kusma, görme bulanıklığı şikayeti olduğu öğrenildi. Yapılan tetkiklerde spot idrarda 3+ proteinüri mevcuttu, karaciğer fonksiyon testleri, LDH, lökosit ve trombosit değerleri normaldi. Hastanın fetal biyometrik ölçümleri son adet tarihi ile uyumlu ve amniyon mayi normal bulundu. Hastanın vajinal muyenesinde collum kapalı ve arkadayd1. NST (non stress test) reaktif, acilde ölçülen tansiyonu 120/80 mmHg idi. Meningeal irritasyon bulguları yoktu ve derin tendon refleksleri normoaktifti. Hastaya nöroloji, göz konsültasyonları ve kranial görüntüleme planlanırken, 15 dakika sonra tansiyon arteriyali $150 / 100$ $\mathrm{mmHg}$ saptand, hastaya nifedipin $10 \mathrm{mg}$ kapsül verildi. Kısa bir süre sonra hastanın bilinci 
kapand 1 ancak konvülsiyon gelișmedi. Hastaya airway takıldı, oksijenize edildi, 4 gram bolus magnezyum sülfat (MgSO4) tedavisi uygulan$d_{1}$, anestezi ve nöroloji konsültasyonları istendi. Hastada fetal distres bulguları geliști, pozisyon verme ve oksijenizasyona rağmen fetal distres bulguları düzelmedi ve ilerledi. Hasta anestezi tarafindan entübe edildikten sonra, 3 ünite kan ayırtılıp acil sezaryene alındı. Sezaryen ile canlı, 1. dakika Apgar skoru 7, 5. dakika Apgar skoru 9 olan sağlıklı 3150 gr erkek bebek doğurtuldu, amniyon mayinde mekonyum yoktu. Operasyonda batında asit ve plasentada dekolman saptanmadi. Peroperatif komplikasyon gelişmedi; uterus çift kat kapatıldı, kanama gelişmedi, kan değerleri de normal gelen hastada batına dren konulmad1. Postoperatif magnezyum sülfat 2 gram/saat idame infüzyon tedavisine devam edildi. Hastanın hipertansiyon ve taşikardisinin postoperatif devam etmesi üzerine antihipertansif (adalat corona $30 \mathrm{mg}$ ) tedaviye eklendi. Göz konsültasyonunda makülada kayma dışında bulgu saptanmadi. Nöroloji konsültasyonunda fokal bulgu saptanmadi, intrakranial kanamayı ekarte etmek ve ayırıcı tanı için kraniyal görüntüleme önerildi. Kraniyal BT de kanama ve kitle saptanmad1. MR da FLAIR (Fluid Attenuated Inversion Recovery) sekansi koronal görüntülerde bilateral parietooksipital bölgede kortikosubkortikal alanda ve solda bazal ganglionlarda sinyal artışı mevcuttu, radyolojik görünüm PRES sendromu ile uyumlu saptand1 (Resim 1,2).

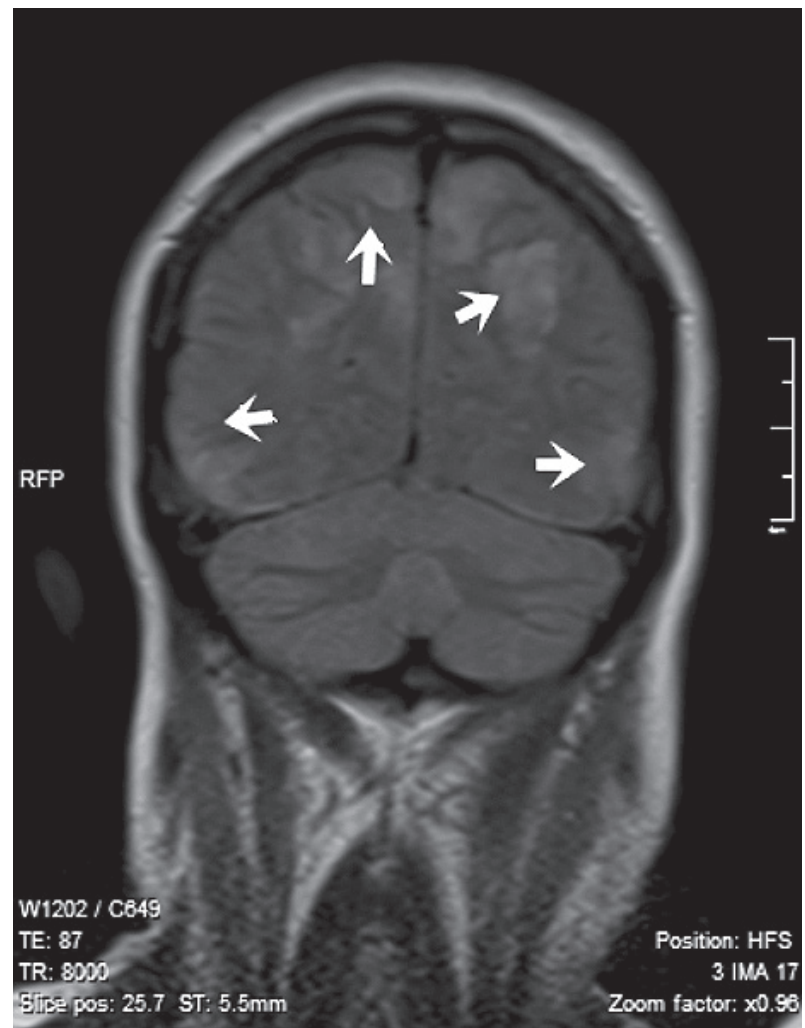

Resim 1. FLAIR koronal imajlarda bilateral parietooksipital bölgede kortikosubkortikal sinyal artışı (hiperintensite) mevcuttur.
MR venografide sinüs ven trombozu saptanmadi. Hastada postoperatif 5. saatte status epileptikus geliști ve bilinç kapandı. Hasta tekrar entübe edilip yoğun bakım ünitesine alındı. Hastanın nöbetleri magnezyum sülfata ek olarak nörolojinin önerisi ile eklenen diazepam tedavisi ile geriledi. Post operatif 12. saatte genel durumu düzelen, görme kaybı gerileyen, tansiyonu normale dönen ve ekstübe edilen hasta servise alınd1. Antihipertansif ve MgSO4 tedavisi postoperatif 48. saatte kesildi. Post operatif 4. günde yapılan kontrol MR'da ilk bulgulara göre belirgin regresyon izlendi ve nöroloji konsültasyonu sonrası hasta taburcu edildi. 1 ay sonraki kontrol kraniyal MR normal saptand.

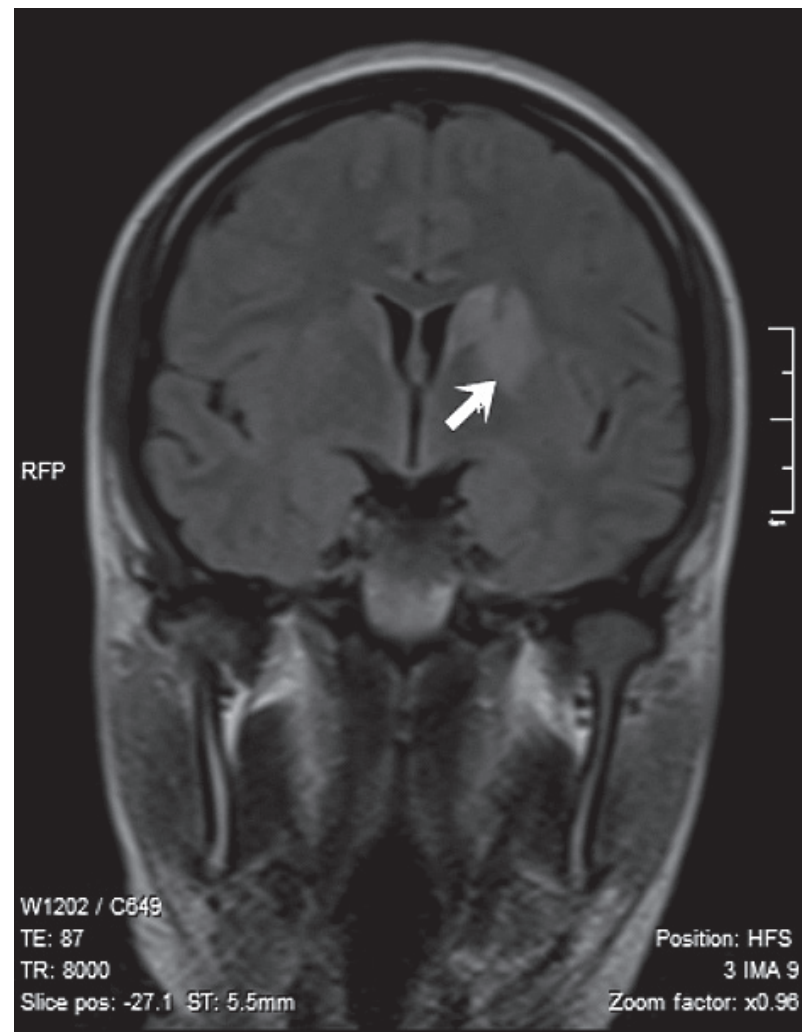

Resim 2. FLAIR koronal imajda solda bazal ganglionlarda sinyal artışı (hiperintensite).

\section{TARTIŞMA}

PRES sendromu nöbetler, görme bozuklukları ve değişken mental durumla seyreden patolojik bir durumdur [1]. PRES tanisi alan, literatürde sunulan vaka sayıları artmasına rağmen halen insidansı tam olarak bilinmemektedir [2-5]. Eklampsi olguları ile PRES arasındaki ilişki ilk olarak 1996 'da Hinchey ve ark. tarafindan bildirilmiştir [4]. Ancak tüm olgulardan görüntüleme yöntemleri istenmediği için halen eklampsi gelişen hastalardaki PRES sıklığı bilinmemektedir [5, 6]. Eklampsi insidansı gelişmiş ülkelerde 2000-3000 doğumda birdir [5]. Literatürde eklampsi gelişen hastalarda primer santral sinir sistemi hasarının PRES olduğuna dair yayınlar giderek artmaktadır [5-7]. 
Mayo Klinikte yapılan bir çalıșmaya göre eklampsi tanısı alan ve görüntüleme yöntemi istenen tüm hastalara klinik ve radyolojik olarak PRES tanısı konulmuştur [5]. Ekawa ve ark. sadece klinik olarak PRES şüphelenilen gebe kadınlardan değil ciddi preeklampsi tanısı olan asemptomatik gebelerden de MR istenmesini önermişler, MR'da serebral ödem saptanırsa eklampsi krizi ve nörolojik semptomlar gelişmeden acil doğum gereklidir sonucuna ulaşmışlardır [3]. Çalışmalarda normal gebelikte maternal dolaşımda artan vazoanjiogenik growth faktör ve sitokinlerin kan beyin bariyerini aşamadığ 1 ancak preeklamptik hastalarda bu bariyer permeabilitesindeki artışa bağlı olarak eklampsideki nörolojik komplikasyonların geliştiği bildirilmiştir $[6,8,9]$.

BT ve MR bulguları posterior alanda özellikle beyaz cevherde reversibl serebral ödemle karakterizedir [10]. Serebral ödemin patofizyolojik mekanizması, artan kan basıncına bağlı artmış serebral kan akımı ve mikrovasküler genişleme sonrası otoregülasyonun bozulması ve plazmanın damar dişına kaçmasıdır [10]. Son çalışmalara göre hipertansiyon ve eklampsinin sebep olduğu hiperperfüzyondan farklı bir mekanizma daha mevcuttur. Bu yeni hipotez direk gelişen vasküler endotel hasarına bağlı kan beyin bariyerinin yıkılmasidır ki bu hastalara hipertansiyon eşlik etmeyebilir [11]. Bu mekanizma sonucu gelişen PRES sendromunda görüntüleme yöntemlerinde de hipoperfüzyon saptanmaktadır. Eklamptik nöbetlerin kan basıncında minimal artışlarla da gelişebileceği ve nöbet etyolojisinde hipertansiyonun tek faktör olmadığ 1 endotel disfonksiyonunun da rol aldığı belirtilmiştir [5]. Ciddi preeklampsi vakalarında konvülsiyonlar gelişmeden önce PRES saptanmış ve bu sendromun eklamptik nöbetlerin sonucu değil öncüsü olduğu sonucuna varılmıştır $[3,5]$. Yine preeklamptik ve eklamptik gebelerde gelişen PRES olgularında kan basinc1, gebe olmayan vakalarda gelişen PRES olgularındaki kan basıncından daha düşük bulunmuștur. Olgumuzda da en yüksek 150/100 mmHg kan basıncı saptanmıştır.

Hastamızın başvuru şikayeti ön planda görme kayb1, kortikal körlüktü. Hipertansiyon ve kortikal körlük ile başvuran hastada ilk akla gelmesi gereken tanılar serebrovaküler hemoraji, eklampsi ve PRES'tir [2]. Preeklampside saptanan göz bulguları ise hipertansif retinopati, eksüdatif retina dekolmanı ve kortikal körlüktür [2]. PRES' e eşlik eden vizüel anormallikler hemianopsi, aura, görsel halüsinasyonlar ve kortikal körlüktür [2]. Kortikal körlüğün sebebi vazojenik ödemdir ve ödemin rezolüsyonu ile semptomlar tamamen kaybolmaktadır [12]. Bizim hastamızda da görme kaybı postpartum 4. gün gerilemiş 1 ay sonra tamamen düzelmiştir. Literatürde nadir olarak görme kaybının nöbetlerden önce geliştiği sunulmuştur [2], bizim hastamızda da nöbetlerden önce ilk bulgu olarak görme kaybı gelişmiş nöbetler ise doğumdan sonra görülmüştür. Hastamızda gelişen nöbetler nadir görülen oksipital lob epilepsisi [13]; nistagmus, gözün bir noktaya sabitlenmesi, ani görme kaybı ve sonrasında gelişen tonik klonik konvülsiyon ile karakterize idi. PRES sendromunda niçin posterior beyin bölgelerinin öncelikle tutulduğu anlaşılamamıştır. İntrakranial arterlerde sempatik innervasyonda bölgesel heterojenite mevcuttur [2]. Anterior dolașım daha iyi sempatik innervasyona sahip olduğu için daha iyi otoregülasyona sahiptir ve posterior loba göre daha az tutulmaktadır [2]. Bizim olgumuzda da posterior lob tutulumu mevcut idi.

PRES olgularında vazojenik ödemi iskemik-toksik ödemden ayırmada difüzyon ağırlıklı görüntüleme kullanılmaktadır [14]. PRES sendromunda MR'da difüzyon anormalliği olmadan infero-posterior, posterior, temporal ve oksipital lob korteksinde FLAIR ve T2 görüntülerde hiperintens, T1 görüntülerde hipointens karakterde simetrik ödem alanları saptanır [14]. BT görüntülemede ise serebral beyaz cevherde ödem hipodens alanlar olarak saptanır [14]. Demirtaş ve ark. PRES olgularını görüntüleme ve patofizyolojiye göre üç gruba ayırmışlardır [14]. Birinci grup hipertansiyona bağlı oksipital lob yerleşimli; ikinci grup normotansif, endotel hasarına bağlı oksipital lob yerleşimli; üçüncü grup üremi gibi metabolik nedenlere bağl1 endotel hasarının rol oynadığı simetrik bazal ganglion tutulumlu olgulardir. Bizim olgumuz bu sinıflamaya göre birinci gruba girmektedir. PRES'te erken teşhis ve tedavi çok önemlidir, aksi halde geri dönüşümsüz beyin hasarı, kronik epilepsi hatta ölüm gelișebilir [1, 15]. Preeklampsiye bağlı gelişen PRES'te temel tedavi kan basincinın düzeltilmesidir $[1,6,16]$. Antihipertansif tedavi olarak intravenöz labetolol, hidralazin veya nikardipin gibi kalsiyum kanal blokerleri önerilmektedir [6]. Ancak bu hastalarda olası organ fonksiyon bozuklukları ve serebral infarkt gelişme riski nedeni ile kan basıncı hızlı düşürülmemelidir [16]. MgSO4, eklampsi ve PRES'te kan-beyin bariyerini koruyarak ve serebral ödemi sinırlayarak antikonvülsan etkilidir [6, 9]. Ancak bazen PRES sendromu oluştuktan sonra nöbetlerin önlenmesinde 
MgSO4 yetersiz kalmaktadır [14]. Literatürde doğum öncesi dönemden itibaren $\mathrm{MgSO} 4$ tedavisi alırken pospartum 30 . saatte gelișen konvülsiyonlar sonrası tanı konulan PRES olgusu sunulmuştur [17]. Tedavide MgSO4'1n yetersiz kalma nedeni PRES sendromunda nöbetlerin serebral iskemik ve ödemli alanlara bağlı gelişmesidir. Tedaviye antiödem ve antiepileptik ilaçlar eklenmesi gerekebilir [14]. Bizim hastamızda da MgSO4 tedavisi alırken postpartum 5. saatte nöbetler başlamış ve diazepam ile kontrol altına alınabilmiştir. HELLP sendromu için deksametazon ve fetal akciğer olgunluğunu sağlamak için betametazon verilen hastalarda santral sinir sistemi fonksiyonlarının daha hızlı normalleștiği gösterilmiștir [6, 18]. Ayrıca steroid serebral ödem tedavisinde de kullanılmaktadır. Tüm bu bulgular ışığında PRES tedavisinde $\mathrm{MgSO} 4$ ve antihipertansif tedavilere potansiyel faydaları için glikokortikoid eklenmesi de tartışılmaktadır $[6,16]$. PRES gelişen miada yakın gebelerde kan basıncının düzeltilmesi, olası konvülsiyonların önlenmesi, hava yolu ve solunum için gerekli önlemlerin alınması sonrası en kısa sürede doğum önerilmektedir $[2,5,16]$. Pre-postpartum dönemde görme kaybı gelişen hastalarda konvülsiyon eşlik etmese de PRES olasılıği akla gelmeli ve görüntüleme yöntemleri istenmelidir [2]. Görüntülemede patolojik bulguların kaybolduğu kontrol grafilerle teyit edilmeli, sendromun tekrarlama olasılığı da akılda tutulmalıdır [16].

Siklıkla preeklampsi zemininde gelişen PRES sendromunu tanımak zor olabilir. Preeklampsili hastalarda sıra dışı nörolojik bulguların varlığında PRES akla getirilmeli, erken teşhisi ve tedavisi ile sekel gelişimi önlenmelidir. Tanıda kranial görüntüleme önemlidir. PRES' e bağlı gelişen nöbetlerin tedavisinde $\mathrm{MgSO} 4$ tek başına yeterli olmayabilir, antiepileptik tedavi eklenmesi gerekebilir. PRES olgularında multidisipliner yaklașım önemlidir, bu nedenle hastaların tersiyer merkezlerde takibi gereklidir.

\section{KAYNAKLAR}

1. Thakur R, Sharma BR, Yuan T, Guiying Z. Posterior reversible leukoencephalopathy syndrome in a pre-eclamptic woman. Case Report Obstet Gynecol 2013;2013:783536. doi: 10.1155/2013/783536. Epub 2013 Feb 20.

2. Ural UM, Balik G, Sentürk S, Ustüner I, Cobanoğlu U, Sahin FK. Posterior Reversible Encephalopathy Syndrome in a Postpartum Preeclamptic Woman without Seizure. Case Report Obstet Gynecol 2014;2014:657903. doi: 10.1155/2014/657903. Epub 2014 Jan 30.
3. Ekawa Y, Shiota M, Tobiume T, Shimaoka M, Tsuritani M, Kotani Y, et al. Reversible posterior leukoencephalopathy syndrome accompanying eclampsia: correct diagnosis using preoperative MRI. Tohoku J Exp Med 2012;226(1):55-8.

4. Hinchey J, Chaves C, Appignani B, Breen J, Pao L, Wang A, et al. A reversible posterior leukoencephalopathy syndrome. $N$ Engl J Med 1996;334(8):494-500.

5. Wagner SJ, Acquah LA, Lindell EP, Craici IM, Wingo MT, Rose $\mathrm{CH}$, et al. Posterior reversible encephalopathy syndrome and eclampsia: pressing the case for more aggressive blood pressure control. Mayo Clin Proc 2011;86(9):851-6.

6. Brewer J, Owens MY, Wallace K, Reeves AA, Morris R, Khan $M$, et al. Posterior reversible encephalopathy syndrome in 46 of 47 patients with eclampsia. Am J Obstet Gynecol 2013;208(6):468.e1-6.

7. Staykov D, Schwab S. Posterior reversible encephalopathy syndrome. Nervenarzt 2012;83(8):1013-20.

8. Amburgey OA, Chapman AC, May V, Bernstein IM, Cipolla MJ. Plasma from preeclamptic women increases blood-brain barrier permeability: role of vascular endothelial growth factor signaling. Hypertension 2010;56(5):1003-8.

9. Euser AG, Cipolla MJ. Magnesium sulfate for the treatment of eclampsia: a brief review.Stroke 2009;40(4):1169-75.

10. Loureiro R, Leite CC, Kahhale S, Freire S, Sousa B, Cardoso EF, et al. Diffusion imaging may predict reversible brain lesions in eclampsia and severe preeclampsia: initial experience. Am J Obstet Gynecol 2003;189(5):1350-5.

11. McKinney AM, Short J, Truwit CL, McKinney ZJ, Kozak OS, SantaCruz KS, et al. Posterior reversible encephalopathy syndrome: incidence of atypical regions of involvement and imaging findings. AJR Am J Roentgenol 2007;189(4):904-12.

12. Do DV, Rismondo V, Nguyen QD. Reversible cortical blindness in preeclampsia. Am J Ophthalmol 2002;134(6):916-8.

13. Plazzi G, Tinuper P, Cerullo A, Provini F, Lugaresi E. Occipital lobe epilepsy: a chronic condition related to transient occipital lobe involvement in eclampsia. Epilepsia 1994;35(3):644-7.

14. Demirtas O, Gelal F, Vidinli BD, Demirtas LO, Uluç E, Ba$\log l u$ A. Cranial MR imaging with clinical correlation in preeclampsia and eclampsia. Diagn Interv Radiol 2005;11(4):18994.

15. Akgün N, Karaman M, Başyiğit S, Yılmaz H, Özcan AA. Posterior reversbl ensefalopati: 2 olgu sunumu. İstanbul Tip Dergisi 2010;2:82-85.

16. Günyeli İ, Erdemoğlu E, Güney M, Mungan T. Yirmi altı haftalik gebelikte preeklampsiye sekonder posterior revesibl ensefalopati (PRES): Bir olgu sunumu. JOPP Dergi 2012;4:80-84.

17. Aygün BK, Baykuş Y, Berilgen S, Kavak B, Celik H, Gürateş B. Posterior Reversible Encephalopathy Syndrome in severe preeclampsia: case report and literature review. J Turk Ger Gynecol Assoc 2010;11(4):216-9.

18. Keiser SD, Owens MY, Parrish MR, Cushman JL, Bufkin L, May WL, et al. HELLP syndrome with and without eclampsia. Am J Perinatol 2011;28(3):187-94. 